\title{
Our understanding and treatment of childhood hydrocephalus circa 1890 via Keating's Cyclopaedia of the Diseases of Children
}

\author{
Mehmet Turgut ${ }^{1} \cdot$ Kevin Tubbs $^{2} \cdot$ R. Shane Tubbs ${ }^{2,3}$ \\ Received: 19 January 2018 / Accepted: 31 January 2018 / Published online: 19 February 2018 \\ (C) Springer-Verlag GmbH Germany, part of Springer Nature 2018
}

\section{Background}

In John M. Keating's (1852-1893) monumental text, Cyclopaedia of the Diseases of Children, published in 1890 , a unique view of the etiology and treatment of childhood hydrocephalus is found in volume four of the tome, which was touted as relying on an international authorship of experts. This fourth and last volume of this book is divided into four parts devoted to the ear, the eye, hygiene, and diseases of the nervous system. Two chapters in this last section of the fourth volume focus on hydrocephalus and its treatment $[1,2]$.

The first chapter, written by Francis Turquand Miles (1827-1903) (Fig. 1 and cover figure), a professor from Maryland and President of the American Neurological Society, is titled: "Hydrocephalus: Dropsy of the Brain, Water on the Brain" [1]. In this chapter, acute hydrocephalus and chronic hydrocephalus are differentiated [1].

Hydrocephalus is noted to follow cases of scarlet fever and tuberculosis [1]. Other associated pathologies included congenital syphilis, rickets, rachitis, and diarrhea [1]. Miles [1] also instructs the reader that constipation might cause or aggravate hydrocephalus and thus

R. Shane Tubbs

shanet@seattlesciencefoundation.org

1 Department of Neurosurgery, Adnan Menderes University School of Medicine, Aydin, Turkey

2 Seattle Science Foundation, 550 17th Avenue, Suite 600, Seattle, WA 98122, USA

3 Department of Anatomical Sciences, St. George's University, St. George, Grenada by treating the constipation with calomel, iodide of potassium, or iodide of sodium that the constipation, and "resultant" hydrocephalus might be improved. Miles also mentions that application of strips of adhesive plaster over the entire head by bloodletting with leeches placed over the mastoid process or by applying ice bags to the head has been used with some "cures" [1].

Recommended surgical treatments of the hydrocephalus included ventricular puncture by drawing off small quantities over a long period of time [1]. He concludes by mentioning that the results of injection of tincture of iodine into the ventricles for hydrocephalic children have not been "encouraging" [1].

In his chapter on the surgical treatment of abnormalities of the brain and spinal cord, Phineas Sanborn Conner (1839-1909) (Fig. 1), US Army surgeon and professor of surgery at the Medical College of Ohio and Dartmouth Medical College, concludes that the administration of oral drugs is seldom or never of any value [2]. He continues by suggesting that the only operative treatment of any use is ventricular puncture via the anterior fontanelle with a needle [2]. Craniotomies were placed one and a quarter inches above Reid's baseline and aiming the needle toward a point two and half inches above the contralateral external acoustic meatus.

Conner [2] depicts one of his own hydrocephalic patients and its mother (Fig. 1). The child was found to have a head that was $106 \mathrm{~cm}$ from the root of the nose to the inion and $69 \mathrm{~cm}$ from ear to ear [2]. $\mathrm{He}$ commented that the great disproportion between the size of the head and that of the face gave a peculiar appearance to the child and that the eyes were carried downward and outward [2]. 
Fig. 1 and cover figure Francis Miles (far left) and Phineas Conner (far right) with drawing of mother and her hydrocephalic child (center) who was treated by Conner. Also shown is a parasagittal MRI of a child with massive hydrocephalus (left) and a skull of a child who died with chronic hydrocephalus (right)

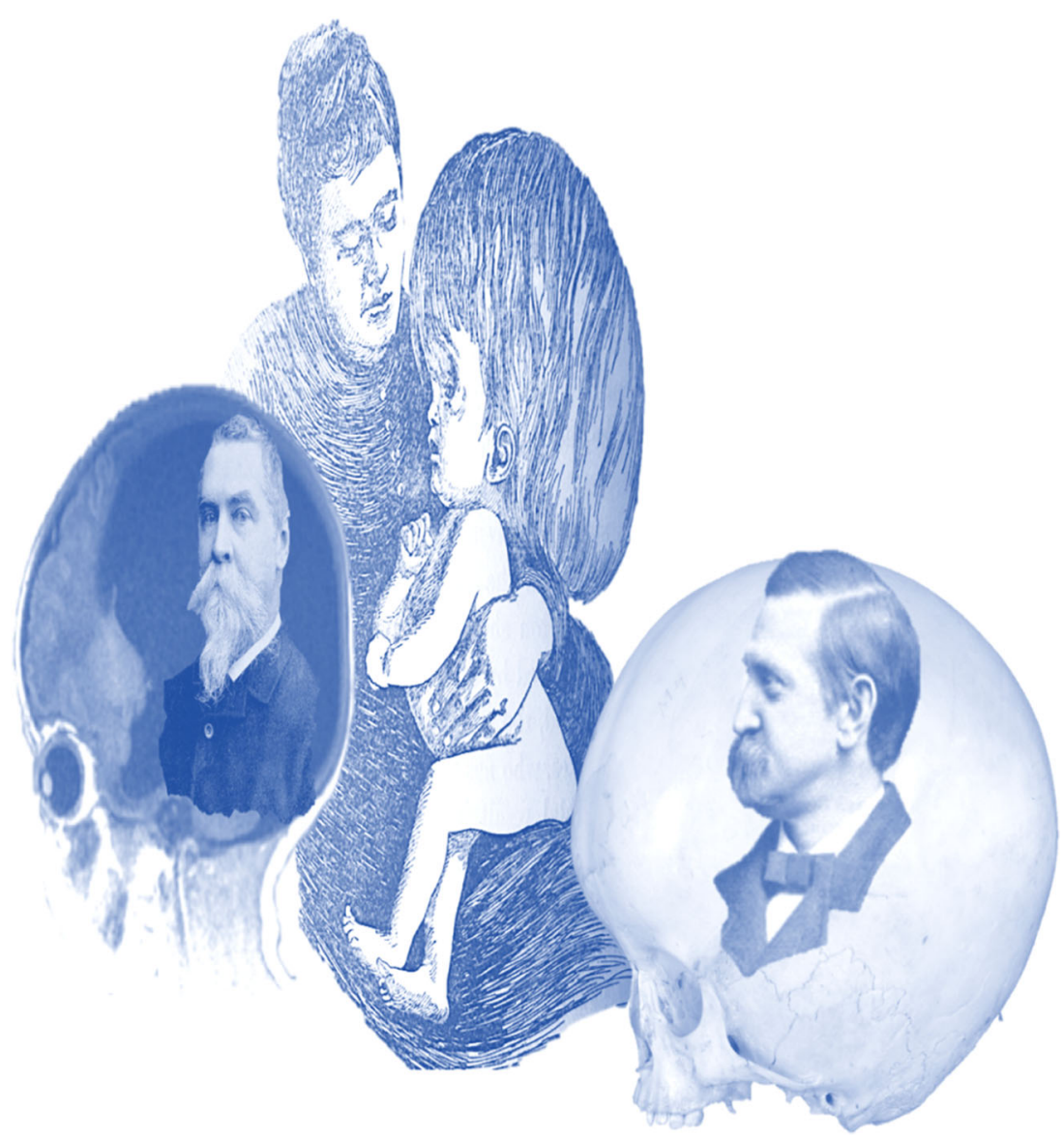

\section{Conclusions}

Keating's textbook Cyclopaedia of the Diseases of Children provides the modern reader with a small window into the understanding and treatment of childhood hydrocephalus over 125 years ago.

\section{Compliance with ethical standards}

Conflict of interest The authors have no conflicts of interest.

\section{References}

1. Miles FT (1890) Hydrocephalus: dropsy of the brain, water on the brain. In: Keating JM (ed) Cyclopaedia of the diseases of children, vol. IV, J. B. Lippincott, Philadelphia

2. Conner PS (1890) The surgical treatment of abnormalities of the brain and spinal cord. In: Keating JM (ed) Cyclopaedia of the diseases of children, vol. IV, J. B. Lippincott, Philadelphia 